This item was submitted to Loughborough's Research Repository by the author.

Items in Figshare are protected by copyright, with all rights reserved, unless otherwise indicated.

\title{
Melt flow behaviour of high density polyethylene nanocomposites with 1D, 2D and 3D nanofillers
}

PLEASE CITE THE PUBLISHED VERSION

http://dx.doi.org/10.1179/2055033215Y.0000000012

\section{PUBLISHER}

(C) Maney

\section{VERSION}

AM (Accepted Manuscript)

\section{PUBLISHER STATEMENT}

This work is made available according to the conditions of the Creative Commons Attribution-NonCommercialNoDerivatives 4.0 International (CC BY-NC-ND 4.0) licence. Full details of this licence are available at: https://creativecommons.org/licenses/by-nc-nd/4.0/

\section{LICENCE}

CC BY-NC-ND 4.0

\section{REPOSITORY RECORD}

Song, Mo, Yasir Q. Gill, and Jie Jin. 2015. "Melt Flow Behaviour of High Density Polyethylene Nanocomposites with 1D, 2D and 3D Nanofillers". figshare. https://hdl.handle.net/2134/18619. 


\title{
Melt flow behaviour of high density polyethylene nanocomposites
}

\author{
with 1D, 2D and 3D nanofillers \\ Y. Q. Gill, J. Jin, M. Song* \\ Department of Materials, Loughborough University, Loughborough, LE11 \\ 3TU, UK
}

\begin{abstract}
The melt flow behaviour of high density polyethylene (HDPE) and its nanocomposites with different kinds of nanofillers (kaolin, bentone, sodium montmorillonite (Na-MMT) clay, carbon nanotubes, graphene oxide and carbon black) is assessed. The dimensional effect (1D, 2D and 3D) of nanofillers on the melt flow singularity of HDPE is investigated. Results reveal that $2 \mathrm{D}$ nanofillers in the polymer matrix have significant improvements on the extrusion window of HDPE. The 2D nanofillers: exfoliated Na-MMT clay and graphene oxide showed the most enhanced melt flow behaviour and processing window for HDPE up to $6.5^{\circ} \mathrm{C}$, the best result reported so far. In comparison to the $2 \mathrm{D}$ nanofillers, $1 \mathrm{D}$ and $3 \mathrm{D}$ nanofillers, and micro-size clays also can broaden the processing window.
\end{abstract}

Keywords: Polymer nanocomposite, melt flow singularity, carbon nanotubes, graphene

*Corresponding author. Email address: m.song@lboro.ac.uk 


\section{Introduction}

In polymer processing, polyethylene (PE) is usually processed at temperatures between 160 to $200^{\circ} \mathrm{C}$, which are much higher than the equilibrium melting point of $\mathrm{PE}$ and are mainly adopted to avoid any interference of melt flow instabilities like high die swell, shark skin etc. Recent studies $^{1-7}$ have shown the presence of an extrusion window for linear PE in between the flow instability and flow induced solidification regions. The extrusion window effect is a specific melt flow singularity in extrusion and is described by the appearance of a pressure reduction occurring at and around $150^{\circ} \mathrm{C}$, while maintaining a constant material throughput without distortion. The existence of an extrusion window for linear PE was first reported by Keller $^{1}$. For polymer processing, the extrusion window has the advantages of an energy efficient processing route (low extrusion pressure and temperature) that can provide the usual continuous flow without any flow instabilities and a smooth extrudate with minimum die swell. On the other hand, the research conducted so far on most of the commercial PE grades has shown that the window effect is conspicuously too narrow about $1 \sim 2^{\circ} \mathrm{C}$ to be adopted in polymer processing in an industrial scale extruder where temperature variation in various zones can be $\pm 2 \sim 3^{\circ} \mathrm{C}$, i.e. the width of window has to be about $5 \sim 6^{\circ} \mathrm{C}$. ${ }^{1-12}$ In order to make the processing industrially viable, the extrusion window has to be broadened to several degrees based on Keller's discovery ${ }^{1}$ so that the thermal fluctuations in the polymer processing can be tolerated.

Conventional rheological theories of extrusion instabilities cannot predict or even explain the observed melt flow singularity phenomenon and its flow criticalities. Lately, the molecular origin of melt flow singularity was studied in details by $\mathrm{Xu}$ et.al ${ }^{11}$. Previous research carried out by Keller $^{5-7}$ had concluded that the capillary flow gives rise to the window effect and the convergence flow at the die entry which can induce a transient mobile hexagonal mesophase into the aligned chains at the die wall surface. The mesophase structure is basically liquid 
crystals which are produced during the transformation of PE melt into fibrous crystals during dynamic cooling inside a capillary experiment. Although Keller et.al. ${ }^{8}$ carried out in-situ wide-angle x-ray analysis during flow in a specially designed capillary rheometer to confirm the formation of such a mesophase, but later studies ${ }^{11}$ indicated that window effect appeared due to shear flow rather than convergence flow. One of the primary factors in enhancing the convergence flow is the die surface entry angle. Xu et al. ${ }^{11}$ carried out detailed flow analysis to investigate the effect of entry angle of die surface on the window and concluded that the extrusion window remains unaffected by the die entry angle. Keller in his extensive work ${ }^{5-7}$ also suggested that the extrusion window can only appear in samples with a molecular weight in the range of from $1.3 \times 10^{5}$ to $1.0 \times 10^{6} \mathrm{~g} / \mathrm{mol}$. Although work carried out on low molecular weight grades of high density PE (HDPE) ${ }^{11}$ and linear low density PE (LLDPE) ${ }^{12}$ have reported the appearance of extrusion window for these polymers. The molecular origin of melt flow singularity phenomenon of linear PE has been attributed to slip flow which can usually promote smooth extrudate production with minimum die swell. The slip flow is produced due to the disengagement of adsorbed chains from the anchored chains at the melt wall interface. This disengagement is also supported by the production of a flow induced mesophase structure.

Recent studies have shown that clay such as sodium montmorillonite (Na-MMT), bentone etc. can be exfoliated in polymers. ${ }^{13-16}$ The nanoscale dispersion of individual clay layers achieved by exfoliation can increase the interaction between the polymer chains and the clay layers which can influence chain dynamics during melt flow in different geometries. The aspect ratio, surface to volume ratio and the relaxation time of clay layers is generally very high and hence they can promote the stretched chain conformation of linear PE at high temperature. However, the effect of exfoliation on the melt flow singularity phenomenon is not clear. In order to clarify the matter, two grades of kaolin with different aspect ratios, 
exfoliated Na-MMT, intercalated bentone clays were selected for the research. The melt flow singularity behaviour in Na-MMT, bentone and kaolin clay/HDPE systems was compared. The inclusion of different shaped fillers can have distinct effect on the rheological properties of polymers and hence alter their flow behaviour e.g. the inclusion of low quantity of Multiwalled carbon nanotubes (MWCNT) in different polymers can reduce the overall viscosity of the polymer melt because their log rolling effect will influence the dynamics of the polymer chains and hence alter the interaction of the polymer chains at the capillary wall. The modification of chain dynamics of polymers at the wall will also be dependent on the shape of the nanofiller being incorporated into the polymer e.g; carbon nanotubes due to their high aspect ratio and tube like structure will influence the engagement of the chains on the capillary wall from the bulk polymer chains in a different way in comparison to the spherical particles of carbon black or the layered structure of graphene.

The research will lead us to know how different shape fillers (1D, 2D and 3D) and their morphologies such as exfoliated and intercalated structures influence the melt flow singularity of HDPE.

\section{Experimental}

Materials and sample preparation

HDPE (Density: $0.96 \mathrm{~g} / \mathrm{cm}^{3}$, MFI: $4.0 \mathrm{~g} / 10 \mathrm{~min}$ ) powder with a particle size on average 850 micron in length was supplied by Exxon Mobil Corporation, UK. Two type of kaolin clay from IMERYS Minerals Ltd were used as nanofillers, i.e., Barrisurf ${ }^{\mathrm{TM}}$ LX (BLX) with a shape factor of 60 and Barrisurf ${ }^{\mathrm{TM}} \mathrm{HX}$ (BHX) with a shape factor of 100. Na-MMT (Cloisite ${ }^{\circledR} \mathrm{Na}+$ ) was supplied by Southern Clay Products, Inc. Bentone was supplied by Elementis Specialties Inc. 
Carbon black (B4040) was purchased from Cobalt Chemicals Company, Belgium. MWCNT chemically modified with hydroxyl group (-OH) about 3.5\% was purchased from Chengdu Institute of Organic Chemistry, Chinese Academy of Science. Ultrafine grinding Graphite (UF4) with a particle size of 4-7 $\mu$ m was purchased from Graphite Kropfmühl AG, Germany. In order to prepare graphene oxide (GO) $2.5 \mathrm{~g}$ of UF4 was mixed with $57.5 \mathrm{ml}$ of concentrated $\mathrm{H}_{2} \mathrm{SO}_{4}$ in an ice bath for 30 minutes. In order to keep the temperature of the mixture below $20^{\circ} \mathrm{C}, \mathrm{KMnO}_{4}$ was added slowly to the mixture. Using a water bath the mixture was then heated to $35 \pm 3^{\circ} \mathrm{C}$ with continuous stirring for $30 \mathrm{~min} .115 \mathrm{ml}$ of distilled water was added drop wise into the mixture which increased the temperature of the mixture to $98{ }^{\circ} \mathrm{C}$. The mixture was stirred for 15 minutes at this temperature. Later $350 \mathrm{ml}$ of distilled water and $25 \mathrm{ml}$ of $30 \% \mathrm{H}_{2} \mathrm{O}_{2}$ solution was added to terminate the oxidation reaction. Graphite oxide (GO) was collected by filtering and was successively washed with $5 \% \mathrm{HCl}$ aqueous solution. $\mathrm{HCl}$ washing was repeated three times until there was no sulphate detected by $\mathrm{BaCl}_{2}$ solution. $\mathrm{GO}$ collected from the mixture was dried at $50{ }^{\circ} \mathrm{C}$ under vacuum for one week. GO was prepared by carrying out ultrasonication of a $1 \mathrm{mg} / \mathrm{ml}$ concentrated dispersion of GO in water with a power of $300 \mathrm{~W}$ for $1 \mathrm{~h}$ at room temperature.

HDPE with 0.2, 0.6, 1 and 2wt.\% of BHX (HH), and with 1wt.\% of BLX (HL1.0), Na-MMT (HMMT1.0), bentone (HB1.0), carbon black (HCB1.0), graphene oxide (HG1.0), MWCNT (HM1.0) composites were prepared by melt blending inside a lab-scale twin screw extruder. Premixing of all the samples was carried out in an aqueous medium according to patent EB2008/003130. The samples received from pre-mixing were then mixed on a lab scale twin screw extruder operating at $110 \mathrm{rpm}$. The temperature profile along the length of extruder was maintained at $160,170,180,190$ and $200{ }^{\circ} \mathrm{C}$, respectively. 


\section{Characterization}

Wide angle x-ray diffraction (WAXD) analysis for the fillers and their composites was carried out using a Brüker AXS, D8 Advance X-ray diffractometer at a generator voltage of 40kV and a current of 40mA. JEOL 2100 FX Transmission Electron Microscope (TEM) was used to analyse the nanofiller structure in the HDPE matrix.

Dynamic cooling rheological analysis of HDPE and its composites was carried out using a twin bore Rosand RH7 capillary rheometer (Rosand Precision Ltd., UK). For rheological analysis the barrels were charged with the sample using a funnel. During charging the sample was compressed thoroughly to avoid any air bubbles build up in the melt. The sample was then heated inside the barrel at $160^{\circ} \mathrm{C}$ for 10 minutes to relax the chains, remove the grain boundary and produce a uniform melt inside the barrel. The melt was then extruded from the capillary rheometer at constant shear rate and a constant cooling rate of $1.5^{\circ} \mathrm{C} / \mathrm{min}$. The extrudate emerging from the bottom of the rheometer was collected for visual analysis and die swell measurements. The die swell of extrudate was measured by an in-situ laser detector situated at $2 \mathrm{~cm}$ under the capillary die. During the measurement, the extrudates were cut off manually to maintain their length at no more than $15 \mathrm{~cm}$ so that the sagging effect can be avoided. The apparent shear stress and apparent shear rate are calculated by using the following equations:

$$
\begin{gathered}
\left(\tau_{w}\right)_{a p p}=\frac{R \nabla P}{2 L} \\
\gamma_{a p p}=\frac{4 Q}{\pi R^{3}}
\end{gathered}
$$

where $\mathrm{R}$ is the radius of the capillary radius, $\mathrm{L}$ is the die length, $\mathrm{Q}$ is the volumetric flow rate, $\nabla$ Pis the pressure difference. 


\section{Results and discussion}

WAXD analysis can provide information about the interlayer d-spacing of the layered fillers upon the formation of composites. The formation of an exfoliated or intercalated structure can be observed from the changes in the position and intensity of the basal peak of the nanofiller. The WAXD pattern of BHX, HDPE and their composites are shown in Figure 1(A). The diffraction peaks which appear at $12.4^{\circ}$ and $8.9^{\circ}(2 \theta)$ are attributed to the basal peak (001) of natural kaolinite. All the diffraction patterns of the composites indicate the presence of kaolinite basal plane, though the peak intensity appears to decrease in low weight percentage filler systems, but for high weight percentage filler systems an increase in the peak intensity is observed. These results suggest that most of the kaolinite retains its natural state and chances of any intercalation can only be observed in low weight percentage filler systems. A number of studies ${ }^{17-20}$, had also reported the absence of an exfoliated or intercalated structure for kaolinite based composites and the main reason is always attributed to the internal structure of kaolinite. Figure 1(B) shows the WAXD patterns of HDPE, NaMMT, bentone and their composites. The (001) diffraction peak for Na-MMT and bentone appear at $7.2^{\circ}$ and $5.5^{\circ}(2 \theta)$, respectively. In both the composites no peak is visible, which indicates that the layered structure of these two clays in the HDPE matrix is completely destroyed and an exfoliated composite structure was formed. 

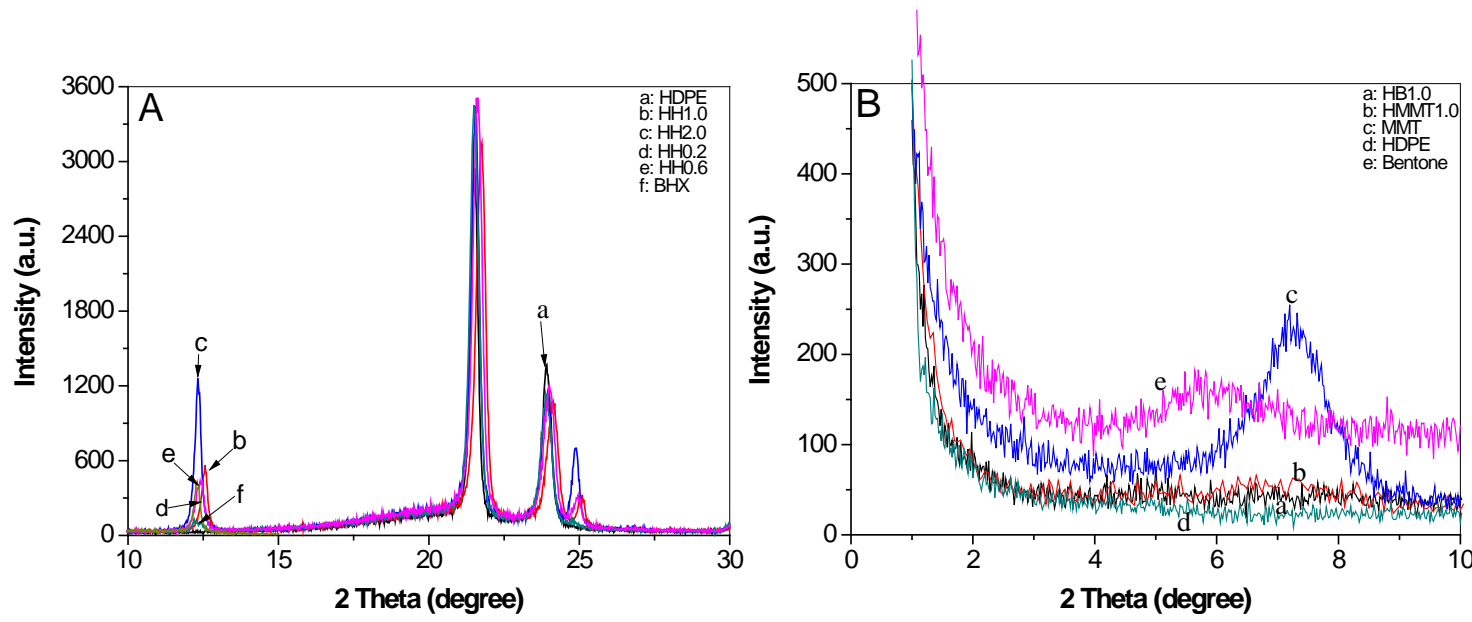

Figure 1: X-ray diffractograms for (A) HDPE, BHX and their composites containing various amounts of BHX clay and (B) Na-MMT, bentone, HDPE and their composites (HH: BHX/HDPE composite; BHX: Barrisurf ${ }^{\mathrm{TM}} \mathrm{HX}$ kaolin clay; MMT: sodium montmorillonite clay; HMMT: Na-MMT/HDPE composite; HB: bentone/HDPE composite)

TEM micrographs for BLX/HDPE, BHX/HDPE, Na-MMT/HDPE and bentone/HDPE composites thin films are shown in Figure 2. The bright region in the TEM micrographs shows the matrix phase and the dark dispersed entities represent the clay phase. The TEM images show that Na-MMT clay was fully exfoliated into individual platelets in the HDPE matrix with very small number of tactoids formation. Both kaolin clays remain in agglomerated state without sign of individual platelets formed and the kaolin tactoids have thickness in microns. In case of HB1.0 an intercalated structure for bentone clay is observed. The thickness for Na-MMT clay tactoids lies in the range of 40-65 nm whereas the tactoids for bentone are much thicker about 70-100nm and number of individual bentone platelets visible is also very small. The TEM micrographs also reveal the uniform distribution of Na-MMT and bentone clay in the HDPE matrix at a very high resolution while the dispersion of clay is much more uneven for the two kaolin clay samples. These results also confirm the results obtained from WAXD analysis, which showed a fully exfoliated structure for HMMT1.0, an intercalated structure for HB1.0 and a traditional filled composite structure for HL1.0 and HH1.0. 

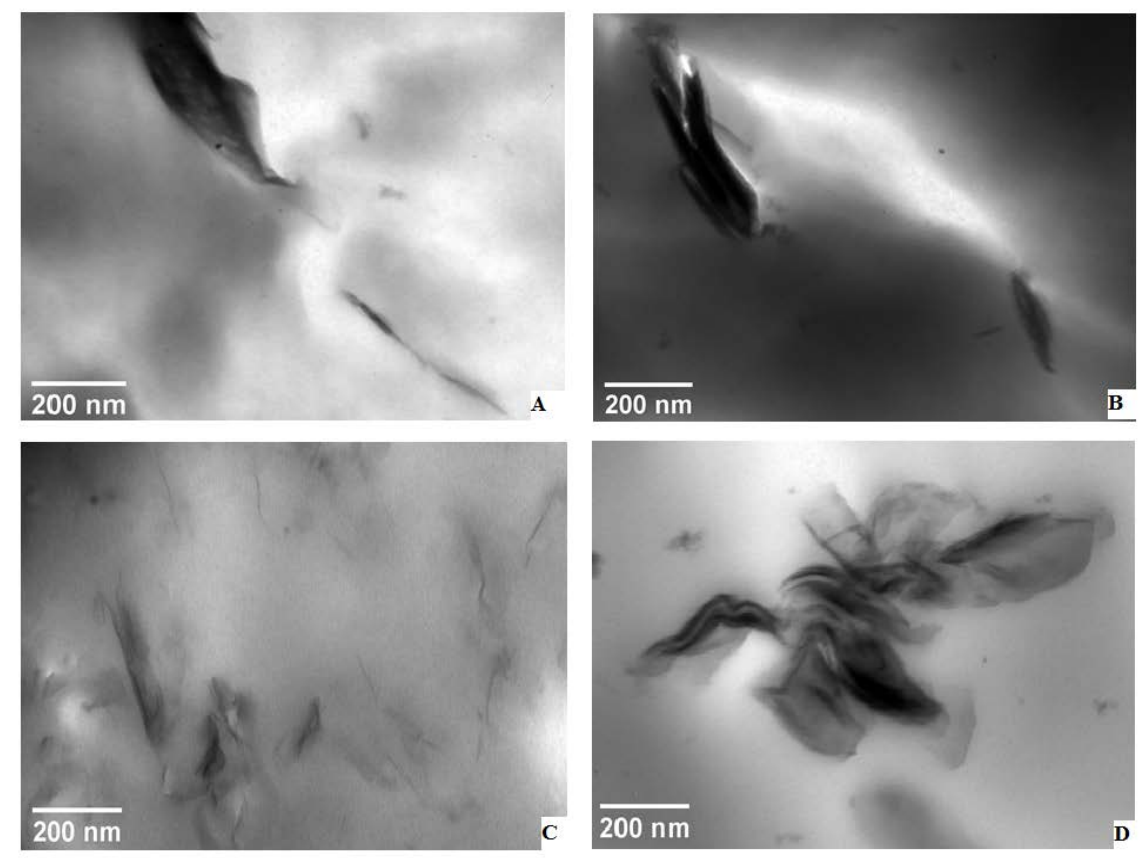

Figure 2: TEM micrographs for (A) BLX/HDPE, (B) BHX/HDPE, (C) Na-MMT/HDPE and (D) bentone/HDPE composites (1wt\% fillers).

In order to understand the effect of carbon based nanofillers on the rheological behaviour of HDPE nanocomposites, TEM analysis of MWCNT (Figure 3 (A)), CB (Figure 3 (C)), and graphene (Figure $3(\mathrm{~B}, \mathrm{D})$ ) nanocomposites was also carried out. The micrographs indicate agglomeration for HM1.0, but also show the uniform distribution of MWCNT throughout the matrix which could have led to better barrier properties and enhanced extrusion window of HM1.0. The distribution of CB inside HDPE was not even visible at higher magnification which shows the nanoscale distribution of spherical CB particles inside HDPE. The distribution of graphene (Figure $3(\mathrm{~B}, \mathrm{D})$ ) shows the unique characteristics of graphene sheets which can only be visualized if the 2D sheets are individually separated from each other. Graphene layers are known to be flexible, transparent and very soft. Due to its soft nature the graphene layers can be folded over by the shearing action of extruder to produce a spool of graphene which is clearly shown in (Figure 3 (D)). This folding could cause a reduction in the aspect ratio of graphene sheets and hence result in diminishing their reinforcing capability. But such spools of graphene have minor visibility throughout the HDPE matrix 
which shows that at the nanoscale most of the graphene sheets had retained their platy structure and hence can contribute to the rheological properties of HDPE.
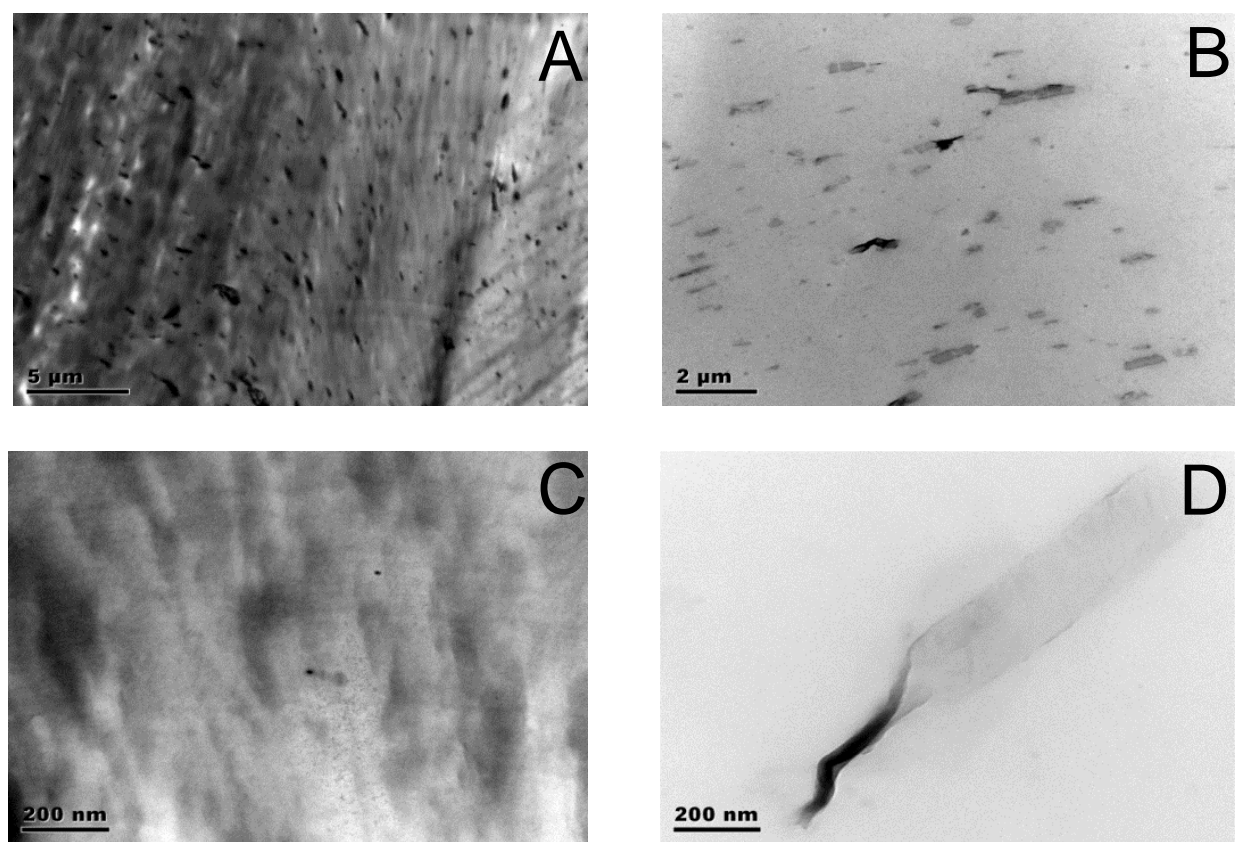

Figure 3: TEM micrographs of (A) MWCNT/HDPE, (B, D) graphene oxide/HDPE and (C) carbon black/HDPE composites (1wt\% fillers)

Figure 4a shows the extrusion pressure vs. temperature data recorded under dynamic cooling conditions for the HDPE with different shear rates. The results show that the melt flow singularity does not appear at low shear rates of $200 \sim 250 \mathrm{~s}^{-1}$ and the extrusion pressure at these shear rates remains stable. These rates are too slow for the coil-stretch transformation to set in in the polymer melt at the die entry region. At $200 \mathrm{~s}^{-1}$ pressure increases steadily with the decrease in temperature, this increase in pressure is attributed to the increase in polymer melt viscosity with cooling. Similar behaviour was observed at $250 \mathrm{~s}^{-1}$. This sort of viscosity behaviour shows a typical Arrhenius type of relationship between viscosity and temperature. Gradual increase in shear rate revealed the window at a shear rate of $275 \mathrm{~s}^{-1}$. At this rate the decrease in pressure during cooling at a temperature of $144.24^{\circ} \mathrm{C}$ was observed because of the high degree of alignment of polymer melt chains along the flow direction in the rheometer die. This is the critical apparent shear rate $\boldsymbol{\gamma}_{\boldsymbol{c}}^{\boldsymbol{w}}$ which corresponds to the onset of extrusion 
window effect. At $275 \mathrm{~s}^{-1}$ and $300 \mathrm{~s}^{-1}$ the window starts at 144.24 and $144.55^{\circ} \mathrm{C}\left(\mathrm{T}_{\mathrm{w}}{ }^{\mathrm{s}}=\right.$ Extrusion Window Starting temperature) and ends at 141.89 and $141.92^{\circ} \mathrm{C}\left(\mathrm{T}_{\mathrm{w}}{ }^{\mathrm{e}}=\right.$ Extrusion Window Ending temperature) and the minimum pressure $\left(\mathrm{P}_{\min }\right)$ observed in the window are 14.44 and 14.98 MPa. $\mathrm{T}_{\mathrm{w}}{ }^{\mathrm{e}}$ also corresponds to the onset of flow induced solidification region where a sudden increase in the pressure is observed. With the increase in shear rate to $325 \mathrm{~s}^{-1}$, the melt flow singularity phenomenon was also observed in between a stick-slip flow region $^{1-7,11}$ in which the pressure oscillates with the decrease in temperature and a flow induced solidification region. Figure $4 \mathrm{~b}$ illustrates the definition and measurement of starting $\left(\mathrm{T}_{\mathrm{w}}^{\mathrm{s}}\right)$ and end $\left(\mathrm{T}_{\mathrm{w}}{ }^{\mathrm{e}}\right)$ points.
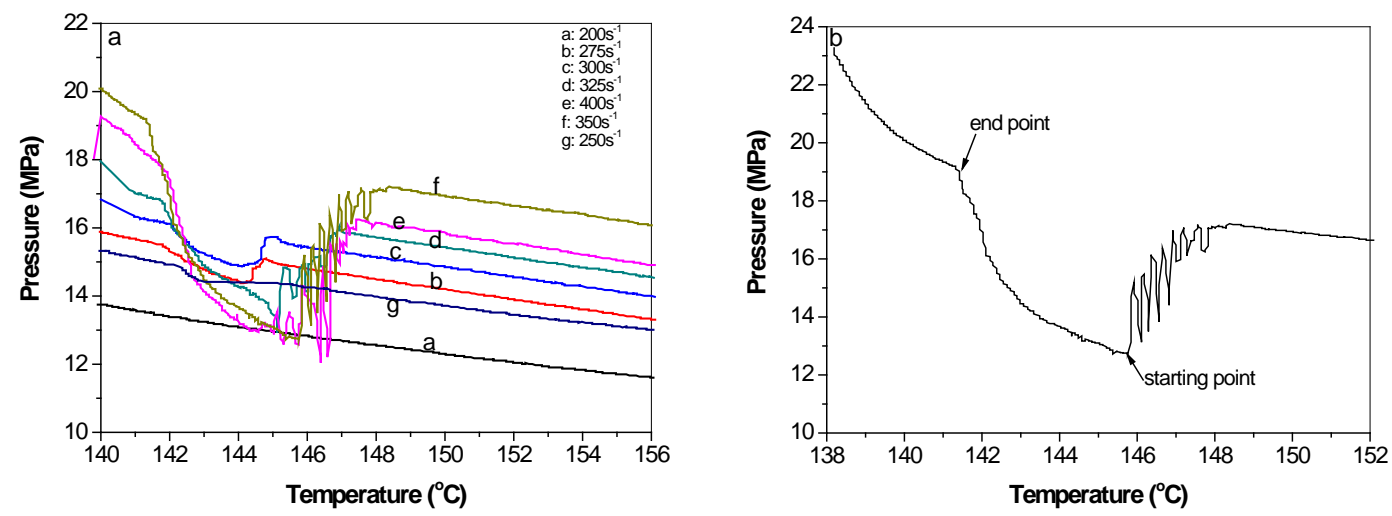

Figure 4: (a) Extrusion Pressure vs temperature curves for the pure HDPE at different strain rates recorded during the dynamic cooling experiment at a constant cooling rate of $1.5^{\circ} \mathrm{C} / \mathrm{min}$ and using a capillary die with geometry: L-D-A:16-1- $\pi$. (b) Illustration of the definition and measurement of starting $\left(\mathrm{T}_{\mathrm{w}}{ }^{\mathrm{s}}\right)$ and end $\left(\mathrm{T}_{\mathrm{w}}{ }^{\mathrm{e}}\right)$ points.

Figure 5 shows the rheological curves for the pure HDPE and its composites with different concentrations of $\mathrm{BHX}$ at a constant strain rate of $350 \mathrm{~s}^{-1}$ recorded during the dynamic cooling experiment. Results show that the addition of BHX clay in the HDPE can influence the extrusion window and the enhancement is much more apparent than increase in strain rates. 
As shown in Figure 4, that the addition of BHX clay influenced not only $\mathrm{T}_{\mathrm{w}}{ }^{\mathrm{s}}$ and $\mathrm{T}_{\mathrm{w}}{ }^{\mathrm{e}}$ temperatures of extrusion window but also $\mathrm{P}_{\min }$.

With the addition of 0.2 and $0.6 \mathrm{wt} \%$ of $\mathrm{BHX}$ clay, $\mathrm{T}_{\mathrm{w}}{ }^{\mathrm{s}}$ and $\mathrm{T}_{\mathrm{w}}{ }^{\mathrm{e}}$ temperatures remains mostly unaffected but an increasing trend in the window over the pure HDPE is observed. With 1wt\% BHX, however, both $\mathrm{T}_{\mathrm{w}}{ }^{\mathrm{s}}$ and $\mathrm{T}_{\mathrm{w}}{ }^{\mathrm{e}}$ temperatures shift and the broadening of window is more pronounced than in 0.2 and $0.6 \mathrm{wt} \%$ BHX clay composites. With $2 \mathrm{wt} \%$ BHX clay, a reduction in the extrusion window and $\mathrm{P}_{\min }$ is observed with $\mathrm{T}_{\mathrm{w}}{ }^{\mathrm{s}}$ shifting to a lower temperature as compared to other composites, while the $\mathrm{T}_{\mathrm{w}}{ }^{\mathrm{e}}$ remains the same as the pure HDPE. The addition of high weight percentage of agglomerated kaolin clay particles will offer resistance to flow because of their ability to behave like irregular pentagon structures. Such structures will also assist in the entanglement of the polymer chains and hence reduce the polymer melt flow.

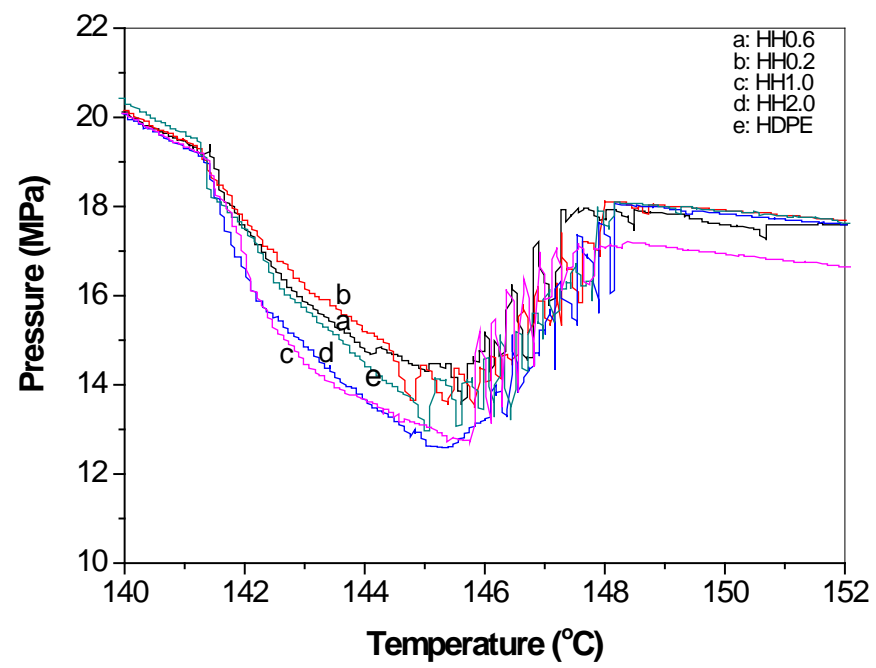

Figure 5: Extrusion pressure vs temperature curves for the pure HDPE and its composites with different concentrations of BHX at a constant strain rate of $350 \mathrm{~s}^{-1}$ recorded during the dynamic cooling experiment at a constant cooling rate of $1.5^{\circ} \mathrm{C} / \mathrm{min}$ and using a capillary die with geometry: L-D-A:16-1- $\pi$ (HH0.2= HDPE with 0.2wt\% BHX clay; HH0.6= HDPE with $0.6 w t \%$ BHX clay and so on) 
Figure 6 shows a comparison of the rheological curves for the HDPE (Fig. 6-d) and its composites with Na-MMT (Figure 6-c), bentone (Figure 6-a), BLX (Figure 6-b) and BHX (Figure 6-e) clay. All the composites contain 1wt\% of clay and were extruded under the same conditions as all BHX composites. The addition of all four different types of clays shows their own individual effects on the extrusion window interval and $\mathrm{P}_{\min }$. With regards to BLX clay, a reduction in the extrusion window is observed due to the movement of both $\mathrm{T}_{\mathrm{w}}{ }^{\mathrm{s}}$ and $\mathrm{T}_{\mathrm{w}}{ }^{\mathrm{e}}$ to higher temperatures in comparison to the pure HDPE. Also $\mathrm{P}_{\min }$ for HL1.0 is only slightly less than that of the pure HDPE. These results indicate that the BLX clay is not uniformly dispersed and its hexagonal shaped agglomerates actually enhance the interaction between the adhered chains on the die wall and the bulk free polymer melt chains due to their tumbling effect. In comparison to the two kaolin clay composites, the effect of intercalated bentone and exfoliated Na-MMT clay on the melt flow singularity is much more pronounced as depicted in Figure 6(a-b). In the presence of bentone and Na-MMT clay, $\mathrm{T}_{\mathrm{w}}{ }^{\mathrm{s}}$ moves to higher temperatures while $\mathrm{T}_{\mathrm{w}}{ }^{\mathrm{e}}$ moves to lower temperatures, which leads to the broadening of the extrusion window. The increase in the extrusion window interval for HM1.0 to $6.5^{\circ} \mathrm{C}$ is the highest yet reported so far. The observation regarding $\mathrm{P}_{\min }$ is that with increasing $\mathrm{Na}$ MMT loading, the pressure decreases within the extrusion window. However the decrease in $\mathrm{P}_{\min }$ and the increase in pressure in the flow induced solidification region for all other composites are minor. 


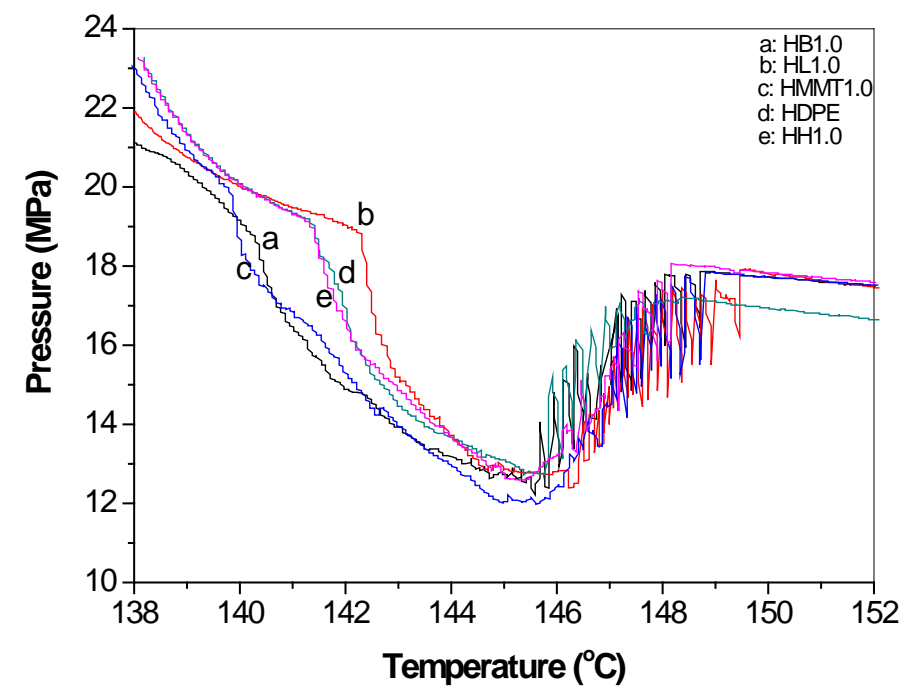

Figure 6: Extrusion Pressure vs temperature curves for the pure HDPE (e) and its composites with (a) Na-MMT , (b) bentone, (c) BLX, and (d) BHX clay at a constant strain rate of $350 \mathrm{~s}^{-1}$ recorded during the dynamic cooling experiment at a constant cooling rate of $1.5^{\circ} \mathrm{C} / \mathrm{min}$ and using a capillary die with geometry: L-D-A:16-1- $\pi$ (HB1.0= HDPE with 1wt\% bentone clay; HL1.0 = HDPE with1wt \% BLX clay; HMMT1.0 = HDPE with 1wt\% Na-MMT clay; HH1.0= HDPE with 1wt \% BHX clay)

The extrusion temperature-pressure profiles recorded during the MFS phenomenon analysis for HDPE and its nanocomposites with CB, MWCNT and graphene are shown in Figure 7. The results show the variation in the extrusion pressure recorded during the dynamic cooling process on capillary rheometer at a strain rate of $350 \mathrm{~s}^{-1}$. The duration of the extrusion window for pure HDPE is $4.3^{\circ} \mathrm{C}$ and the minimum extrusion pressure recorded during the window is 12.78 MPa. The extrusion window observed for HM1.0 and HG1.0 (5.6 and $6.4{ }^{\circ} \mathrm{C}$ ) are broader than HDPE, whereas in case of HCB, a reduction $\left(3.3^{\circ} \mathrm{C}\right)$ in the extrusion is observed. This reduction explains the effect of particle shape in extending and aligning the polymer melt chains tethered at the die wall which ultimately leads to enhanced slip flow of the disengaged bulk polymer chains on the tethered polymer melt chains. 


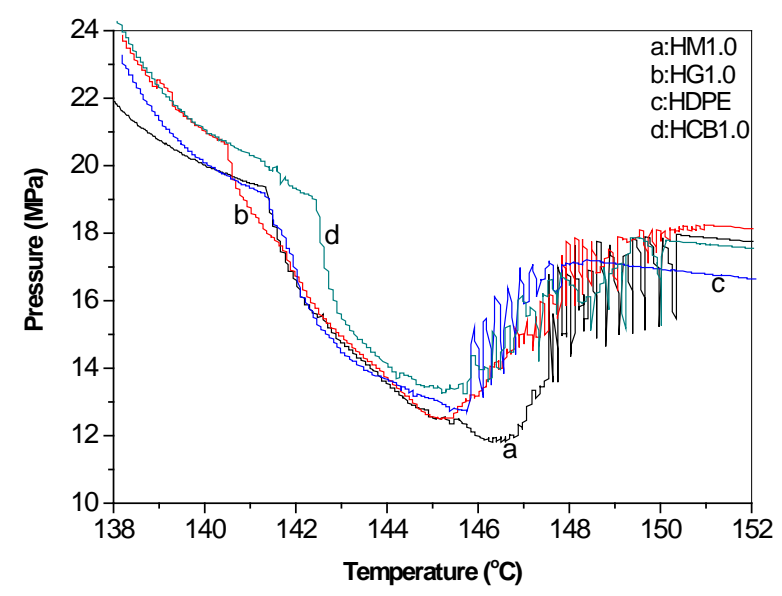

Figure 7: Extrusion Pressure vs temperature curves for the pure HDPE (c) and its composites with (a) MWCNT , (b) GO and (d) CB at a constant strain rate of $350 \mathrm{~s}^{-1}$ recorded during the dynamic cooling experiment at a constant cooling rate of $1.5^{\circ} \mathrm{C} / \mathrm{min}$ and using a capillary die with geometry: L-D-A:16-1- $\pi$ (HM1.0 = HDPE with 1wt\% MWCNTs; HG1.0= HDPE with 1wt \% graphene; HCB1.0= HDPE with 1wt \% carbon black)

Due to their circular shape CB enhance the engagement between the tethered and the bulk polymer chains and hence reduce the overall slip flow for the bulk polymer chains. On the other hand the elongated and platy nature of MWCNT and graphene can align the tethered chains and also provide more slippage on surface to the bulk polymer chains. As detailed earlier on, that the spherical CB particles provide more friction to the polymer chains by promoting entanglements and hence the flow of $\mathrm{CB}$ composites through the die will be resisted more in comparison to the graphene and carbon nanotubes nanocomposites.

Another proof of the resistance offered by the CB particles to appearance of slip flow is the minimum extrusion pressure drop of $13.24 \mathrm{MPa}$, this value is even higher than that of pure HDPE and is an indication of higher shear stress which is required to transform the stick-slip flow to slip flow of extrusion window. In case of HCB1.0, the extrudate diameter observed is slightly larger than pure HDPE. Table 1 shows the rheological data obtained from the dynamic cooling experiment of the HDPE and all its composites. 
Table 1: Rheological data obtained from the dynamic cooling experiment of HDPE and all its composites (HH0.2 = HDPE with 0.2wt \% BHX clay; HL1.0 = HDPE with1wt \% BLX clay; HMMT1.0 = HDPE with 1wt \% Na-MMT clay; HB1.0 = HDPE with 1wt $\%$ bentone clay; HG1.0 = HDPE with 1wt \% graphene; HCB1.0= HDPE with 1wt \% carbon black; HM1.0 = HDPE with 1wt \% MWCNTs)

\begin{tabular}{|c|c|c|c|c|c|}
\hline Sample & $\begin{array}{c}\text { Strain } \\
\text { rate }(1 / \mathrm{s})\end{array}$ & $\begin{array}{c}T_{w}^{S} \\
\left.\text { ( }^{o} \mathrm{C}\right) \\
\text { (starting } \\
\text { point) }\end{array}$ & $\begin{array}{l}T_{w}^{e}\left({ }^{0} \mathrm{C}\right) \\
\text { (end } \\
\text { point) }\end{array}$ & $\begin{array}{c}\text { Processing } \\
\text { Window } \\
\text { ( } \mathrm{C} \text { ) }\end{array}$ & $\begin{array}{c}P_{\min } \\
\text { (MPa) }\end{array}$ \\
\hline \multirow{7}{*}{ HDPE } & 200 & - & - & - & - \\
\hline & 250 & - & - & - & - \\
\hline & 275 & 144.24 & 141.89 & 2.35 & 14.44 \\
\hline & 300 & 144.55 & 141.92 & 2.63 & 14.92 \\
\hline & 325 & 145.12 & 141.6 & 2.82 & 13.43 \\
\hline & 350 & 145.75 & 141.42 & 4.33 & 12.78 \\
\hline & 400 & 145.02 & 142.07 & 2.95 & 12.94 \\
\hline НH0.2 & 350 & 144.75 & 141.29 & 3.46 & 14.92 \\
\hline HH0.6 & 350 & 145.54 & 141.42 & 4.12 & 14.33 \\
\hline HH1.0 & 350 & 146.01 & 141.32 & 4.69 & 12.59 \\
\hline HH2.0 & 350 & 145.01 & 141.36 & 3.65 & 12.96 \\
\hline HL1.0 & 350 & 146.2 & 142.31 & 3.89 & 12.72 \\
\hline HMMT1.0 & 350 & 146.4 & 139.87 & 6.53 & 11.97 \\
\hline HB1.0 & 350 & 145.5 & 140.29 & 5.21 & 12.66 \\
\hline HG1.0 & 350 & 146.72 & 140.36 & 6.36 & 12.48 \\
\hline HCB1.0 & 350 & 145.76 & 142.45 & 3.31 & 13.24 \\
\hline HM1.0 & 350 & 147.56 & 141.25 & 6.31 & 11.81 \\
\hline
\end{tabular}


A schematic of extrusion pressure vs. temperature for the HDPE flowing in capillary rheometer under dynamic cooling at a constant shear rate is shown in Figure 8. The plot shows the four different flow regions encountered at or around the typical melt flow singularity phenomenon: (1) stick flow, (2) stick-slip flow, (3) slip flow and (4) flow induced solidification. ${ }^{5-7,11}$ In the stick flow region extrusion pressure increases with decrease in the temperature and we have a typical liquid polymer melt inside the capillary die whose viscosity increases with decrease in temperature and in this region the viscosity and the temperature obey an Arrhenius type relationship. ${ }^{5-7,11}$

$$
\eta=A e^{E_{a} / R T}
$$

In the above equation $\eta$ is the shear viscosity, $E_{a}$ is the melt/solid state flow activation energy, $\mathrm{R}$ is the universal gas constant and $\mathrm{T}$ is the flow temperature. In the stick flow region the extrudate surface becomes rough and it shows surface melt fracture with loss of gloss and the die swell also increases with the decrease in temperature. In the stick-slip flow region pressure oscillations with the decrease in temperature are observed and extrudate obtained consists of alternating regions of melt fracture and smooth extrudate surface. In the slip flow region the phenomenon of melt flow singularity is observed and this region is the extrusion window where a reduction in pressure is observed along with a smooth and glossy extrudate with minimum die swell is obtained. The extrusion window is observed in a small region with the transformation of the polymer melt into liquid crystal mesophase. Molecular origin of the singularity is associated with the slip flow phenomenon ${ }^{11}$ which is influenced by the chain attachment to the die surface and its detachment from the bulk polymer melt. Thus the singularity is influenced by the interfacial energy between the molecular chains and the wall. Brochard and de Gennes ${ }^{21}$ and Drda and Wang ${ }^{22}$ have proposed theories on the possibility of chain attachment to the wall surface and its disengagement from the polymer melt above a 
critical shear rate or shear stress. The disengagement process of the chains will be strongly dependent of the topological constraints between the adsorbed chains and the surrounding chains in the bulk, which would be dependent on molecular characteristics and flow conditions. Out of the extrusion window a rapid increase in pressure is observed due to the formation of solid fibrous crystal which leads to flow induced solidification of the polymer melt and causes the viscosity and extrudate diameter increases rapidly. The solidification takes place because the temperature reaches the static solidification temperature during cooling and orientation induced crystallization causes the viscosity to increase because of fibrous crystal formed inside the melt.

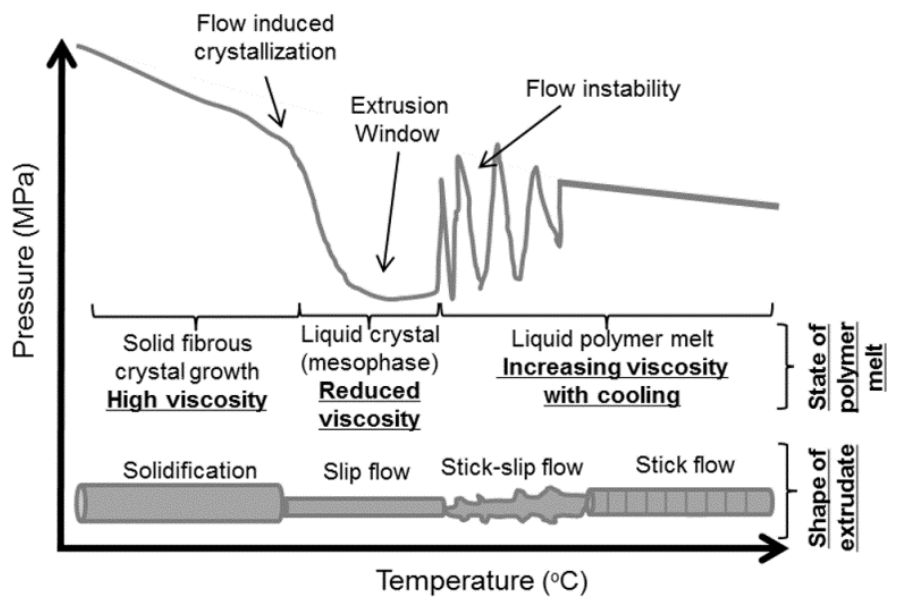

Figure 8: Extrusion Pressure vs. temperature schematic plot, demonstrating melt flow singularity phenomenon of HDPE in capillary rheometer. The bottom of the graph shows the four different flow regions encountered at or around the MFS phenomenon i.e. (1) stick flow, (2) stick-slip flow, (3) slip flow and (4) flow induced solidification, along with the state of polymer melt and the shapes of the extrudate achieved in the different stages of extrusion.

When the polymer chains are aligned, the small amount of filler particles added will act as lubricant surface that can effectively reduce the friction between the polymer chains and hence assist in the flow of polymer melt through the die (Figure 9-A). The introduction of individual clay and graphene layers produced by exfoliation or intercalation between the polymer chains can effectively decrease the overall friction in the system and hence the 
polymer chains will flow more easily during the extrusion window. If the polymer chains are entangled (Figure 9-B) the addition of exfoliated clay and graphene layers will produce large internal friction which leads to energy dissipation in composites and can restrict the movement of polymer chains. ${ }^{23}$ Also the filler agglomerates act like hexagonal particles (Figure 9-C) which perturb the orientation of the adsorbed chains and also favour their entanglement with the bulk polymer chains and hence cause a reduction in the extrusion window.

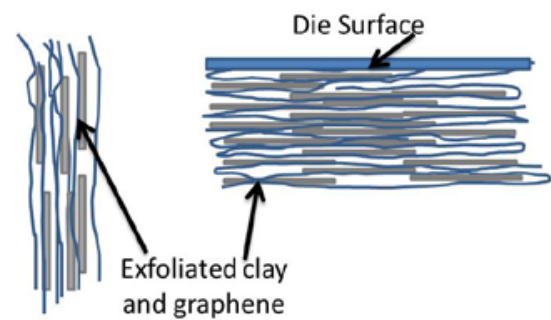

(A) layers

(B)

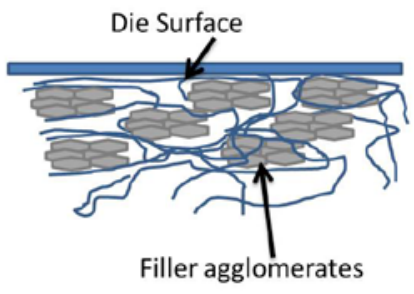

(C)

Figure 9: Schematic of the interaction: (a) exfoliated clay and graphene layers and the bulk polymer melt chains, (b) exfoliated clay and graphene layers along with adsorbed polymer melt chains on the die surface, (c) hexagonal shaped filler agglomerates and the adsorbed polymer melt chains on the die surface.

The polymer melt due to their entangled structure has a short relaxation time ${ }^{11,24}$ which can be altered significantly by the addition of nanofillers. The large platy structure of clay and graphene layers with high aspect ratio and high relaxation time ${ }^{11,24}$ can help with alignment of polymer chains during flow and also help maintain the stretched chain confirmation of the adsorbed chains at the die wall. Due to their structure the exfoliated clay and graphene layers could also help in the orientation of the adsorbed chains at the capillary wall because these adsorbed chains can easily wrap themselves around the clay and graphene layers and that would ultimately stop their entanglements with the bulk polymer melt chains, which would lead to better flow and minimum die swell for longer temperature intervals. 
The critical stress $\sigma_{c}$ for wall slip is presented by Brochard and de Gennes theory on wall-slip at the metal-solid interface, ${ }^{21}$ as:

$$
\sigma_{c}=v K_{B} T /\left(N_{e}^{\frac{1}{2}} \alpha\right)
$$

where $v$ is the number density of molecular chains adsorbed at the interface, $\mathrm{N}_{\mathrm{e}}^{\frac{1}{2}} \alpha$ is the entanglement distance.

The percentage area covered by the adsorbed chains at the metal wall and melt interface $(\theta)$ is obtained using the single layered adsorption model: ${ }^{21}$

$$
\theta=b v_{0} /\left(1+b v_{0}\right)
$$

where $\mathrm{v}_{0}$ is the number density of molecular chains in the bulk polymer melt and $\mathrm{b}$ indicates the intensity of adsorption. In case of polymer melt, strong interface adhesion on capillary wall is observed, which shows that $b v_{0}>>1$, and hence $\theta=1$, which basically means saturated adsorption of molecular chains on capillary wall. So for the HDPE melt $v$ would remain same even under the influence of various nanofillers and varying temperature. Also since the amount of fillers used is very low so that could also not affect the HDPE melt $\mathrm{v}$. So in case of HM1.0 the lower value of $\mathrm{P}_{\min }$ obtained, which indicates lower wall shear stress for slip flow is due to increasing entanglement distance which will help in the flow of bulk polymer chains by separating them from the adsorbed chains on the capillary wall.

As the temperature is reduced below the processing window temperature $\left(<142^{\circ} \mathrm{C}\right)$ the extrusion pressure shoots up dramatically and a considerable increase in the die swell of the extrudate is observed. In Fig. 10 the die swell ratio for the pure HDPE at three different temperatures $\left(140^{\circ} \mathrm{C}, 143^{\circ} \mathrm{C}, 160^{\circ} \mathrm{C}\right)$ is plotted against the strain rate (extrusion speed) maintained during the cooling process. The curve for $160^{\circ} \mathrm{C}$ represents the normal processing behaviour for the HDPE melt in a capillary rheometer where the die swell gradually increases 
with increase in shear rates. The die swell (B) and the temperature of extrusion in a capillary rheometer are correlated by the following linear relationship: ${ }^{16}$

$$
B=\alpha_{1}-T \beta_{1}
$$

Where $\alpha_{1}$ and $\beta_{1}$ are coefficients related to material properties. It is also clear from Fig. 10 that in the flow induced solidification temperature range $\left(140^{\circ} \mathrm{C}\right)$ the die swell increases quite steeply with increase in strain rates, whereas in the extrusion window temperature range $\left(144^{\circ} \mathrm{C}\right)$ the die swell remains more or less constant. This result provides another proof for the liquid crystalline nature of the polymeric melt in the processing window because the liquid crystal polymers because their chain extension characteristics do not show any die swell regardless of the strain rate employed.

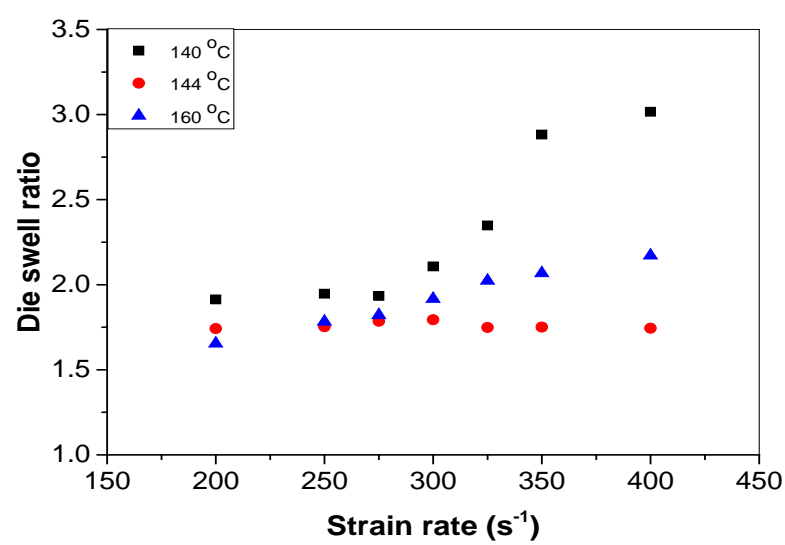

Figure 10: Plot of die swell ratio as a function of the strain rate maintained during dynamic cooling experiment for HDPE at three different extrusion temperatures.

Figure 11 shows the extrudate profile for the pure HDPE, HM1.0 and $\mathrm{HH} 1.0$ at $139^{\circ} \mathrm{C}, 143^{\circ} \mathrm{C}$ and $160^{\circ} \mathrm{C}$. The three temperatures selected corresponds to the three distinct flow regimes: flow induced solidification, extrusion window and stable melt flow respectively. It is generally accepted ${ }^{13,16}$ that the die swell occurs due to the elastic recovery of the polymer melt after it emerges from the die. 


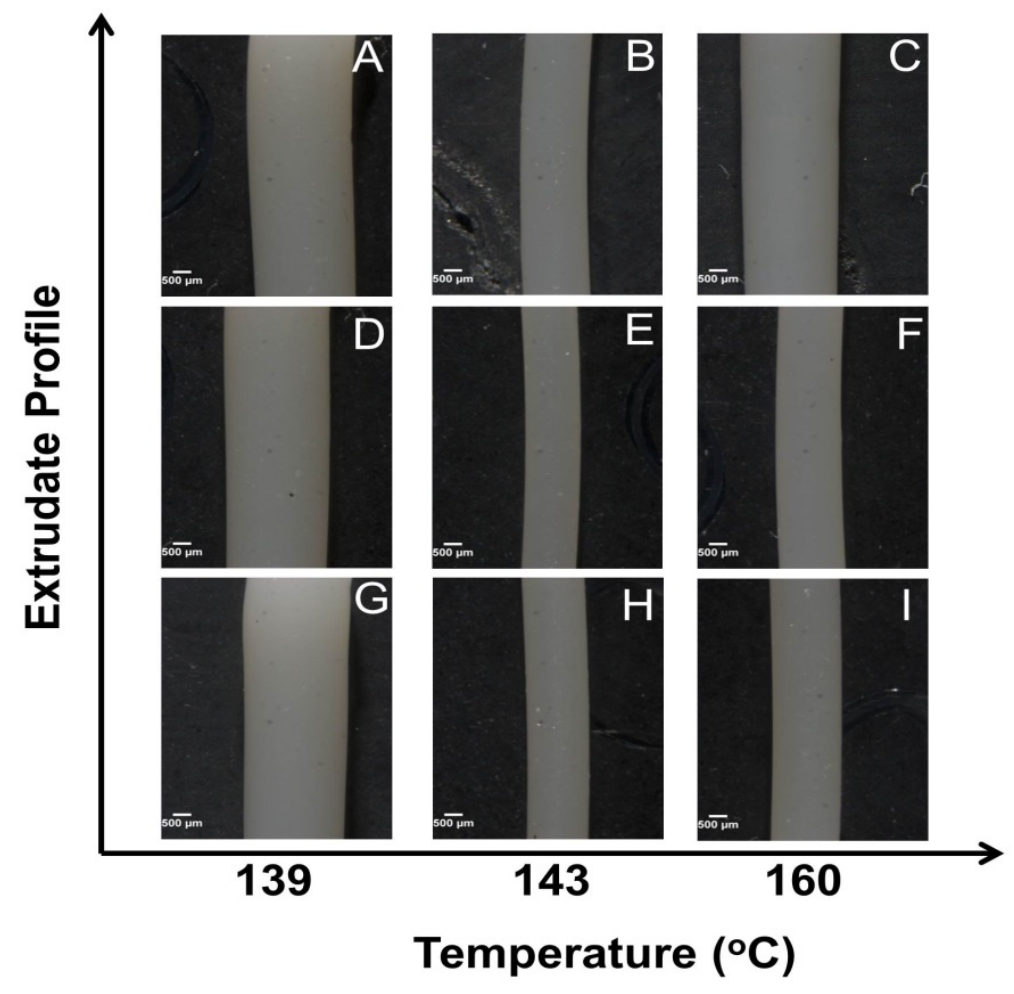

Figure 11: Extrudate profiles of the pure HDPE (A-C), HM1.0 (D-F) and HH1.0 (G-I) at three different temperatures $139{ }^{\circ} \mathrm{C}, 143{ }^{\circ} \mathrm{C}$ and $160{ }^{\circ} \mathrm{C}$ with a strain rate of $350 \mathrm{~s}^{-1}$

The inclusion of clay and graphene layers with high surface area and ease of movement in comparison to the entangled polymeric chains can increase the energy dissipation of the composites at a given shear rate. ${ }^{23}$ Also in the extrusion window, slip flow of polymeric melt takes place and most of the adsorbed chains remains tethered on the die wall and free chains slip over these tethered chains which are extruded out with minimum die swell as shown in Figure 12(A-C). The die swell of extrudate could depend on the disentanglement degree of the free chains. The addition of oriented high surface area clay and graphene layers will limit the elastic recovery of the stretched free polymeric chains. 


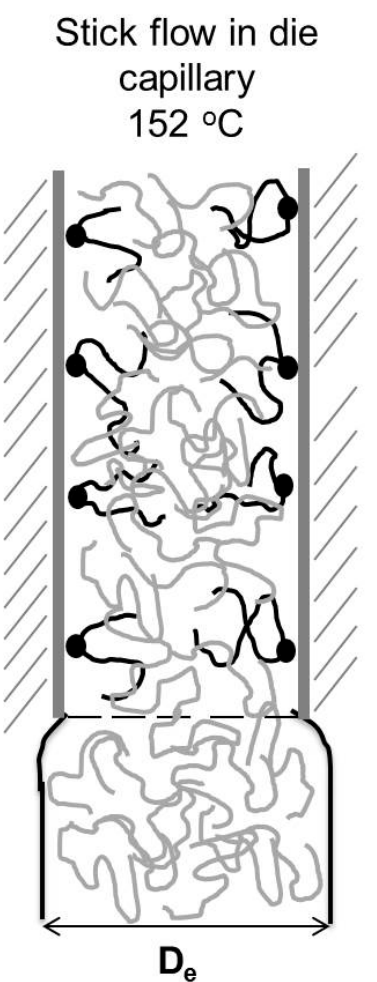

(A)

\section{Slip flow in die \\ capillary \\ $143^{\circ} \mathrm{C}$}

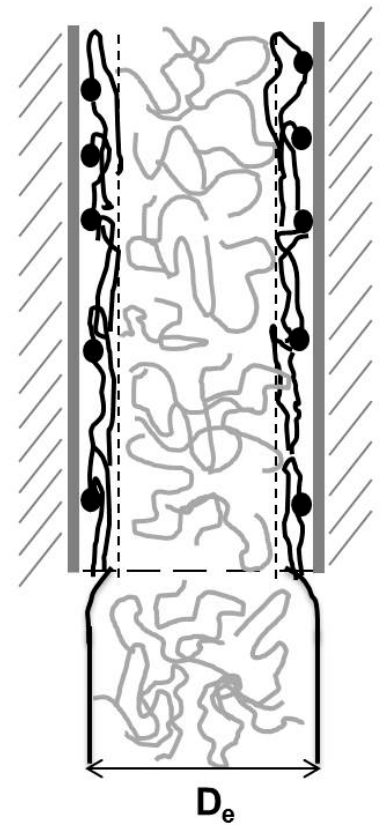

(B)
Slip flow in die capillary

$143^{\circ} \mathrm{C}$

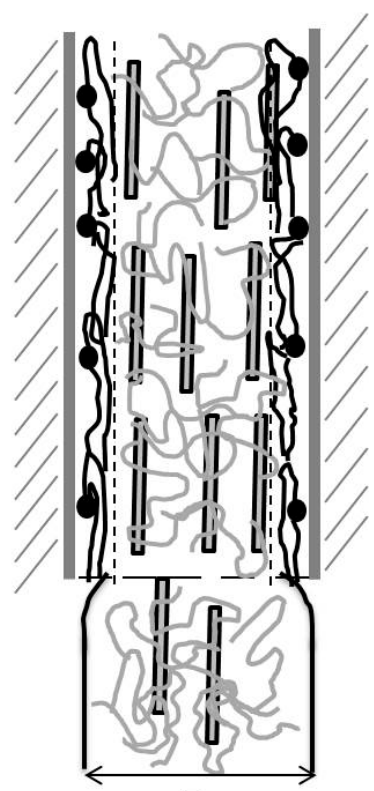

$D_{e}$

(C)

Figure 12: Schematic of the difference in the extrudate diameters $\left(D_{e}\right)$ obtained in $(a)$ the stick flow at $152{ }^{\circ} \mathrm{C}$, (b) slip flow at $143{ }^{\circ} \mathrm{C}$ and (c) slip flow at $143{ }^{\circ} \mathrm{C}$ in the presence of clay and graphene layers with a strain rate of $350 \mathrm{~s}^{-1}$. The black dots represent the end tethered chains on the die wall, while the entangled lines represent the polymer chains.

In case of HCB1.0, the higher value of $\mathrm{P}_{\min }$ obtained indicates higher wall shear stress for slip flow and is due to the decreasing entanglement distance which will resist in the flow of bulk polymer chains by entangling them with the adsorbed chains on the capillary wall. In case of MWCNT and graphene based composites the increase in the extrusion window is also attributed to their high aspect ratio and relaxation time, which helps in stretched confirmation and alignment of chains tethered to the metal wall. Also the aligned chains can be easily wrapped up around graphene layers and the MWCNT, making the tethered chains unavailable for entanglements with the bulk of the polymer chains. The results indicate that die swell is minimised in the extrusion window temperature interval and it increases dramatically during the flow induced solidification. The difference between the die swell in 
the processing window and the stable melt flow regime indicate that the polymer melt extrudes more easily than at high processing temperature in the processing window, and thus validates the applicability of the processing window as an authentic method of processing.

\section{Conclusions}

The melt flow singularity of HDPE and its composites with different kinds of clay and carbon based nanofillers was investigated. The mechanism of melt flow singularity was analysed with respect to the strain rate and filler content dependence of the critical points of the extrusion window. The addition of nanofillers resulted in the expansion of extrusion window of HDPE. When the polymer chains are aligned, the small amount of filler particles added will act as lubricant surface that can effectively reduce the friction between the polymer chains and hence assist in the flow of polymer melt through the die. Especially, the introduction of individual clay and graphene layers produced by exfoliation or intercalation between the polymer chains can effectively decrease the overall friction in the system and hence the polymer chains will flow more easily during the extrusion window. If the polymer chains are entangled the addition of exfoliated clay and graphene layers will produce large internal friction which leads to energy dissipation in composites and can restrict the movement of polymer chains. The exfoliated Na-MMT clay and graphene/HDPE composites showed the most enhanced window up to $6.5^{\circ} \mathrm{C}$, the best result reported so far, due to the larger interfacial contact area between the polymer chains and the surface of clay and graphene layers in the matrix.

Acknowledgement: We thank EPSRC (UK) for providing funding (EP/G042756) for this work 


\section{References}

1. A.J.Waddon and A.J.Keller.: Polym. Sci., Polym. Phys. 1990, 28, 1063-1073.

2. K.A.Narh and A.J.Keller: Polymer, 1991, 32, 2512-2518.

3. K.A. Narh and A.J.Keller: J. Mater. Sci. Lett., 1991; 10(22): 1301-1303.

4. A.J. Waddon and A.J. Keller: Polym. Sci. Polym. Phy, 1992, 30, 923-929.

5. J.W.H.Kolnaar and A.J.Keller: Polymer, 1994, 35, 3863-3874.

6. J.W.H.Kolnaar and A.J.Keller: Polymer, 1995, 36, 821-836.

7. J.W.H.Kolnaar and A.J.Keller: Polymer, 1997, 38, 1817-1833.

8. J.W.H.Kolnaar and A.J.Keller: J. Non-Newtonian Fluid Mech., 1996, 67, 213-240.

9. J.W.H.Kolnaar, A.J.Keller, S.Seifert, C.Zschunke and H.G.Zachmann: Polymer, 1995, 36, 3969-3974.

10. H.M.M.van Bilsen, H.Fischer, J.W.H.Kolnaar and A.J.Keller: Macromolecules, 1995, 28, 8523-8527.

11. H.Xu, A.Lele and S.Rastogi: Polymer, 2011, 52, 3163-3174.

12. S.Pudjijanto and M.Denn: J. Rheol., 1994, 38, 1735-1744.

13. C.Dazhu, Y.Haiyang, H.Pingsheng and Z.Weian: Compos. Sci. Technol., 2005, 65, 15931600.

14. J.Aalaie, S.Malmir and M.Hemmati: J. Macromol. Sci. Phys., 2012, 52, 1-12.

15. G.Galgali, C.Ramesh and A.Lele: Macromolecules, 2001, 34, 852-858.

16. N.Muksing, M.Nithitanakul, B.P.Grady and R.Magaraphan: Polym. Test., 2008, 27, 470479.

17. L.Cabedo, E.Giménez, J.M.Lagaron, R.Gavara and J.J.Saura: Polymer, 2004, 45, 52335238.

18. L. Domka, A.Malicka and N.Stachowiak: Pol. J. Chem. Tech., 2008, 10, 05-10.

19. L.Feijoo, P.Villanueva and E.Gime: Macromol. Symp., 2006, 233, 191-197.

20. M.P.Villanueva, L.Cabedo, J.M.Lagaro'n and E.Gime'nez: J. App. Polym. Sci., 2010, $115,1325-1335$.

21. F.Brochard and P.G.de Gennes: Langmuir, 1992, 8, 3033-3037.

22. P.P.Drda and S.Q.Wang: Phys. Rev. Lett., 1995, 75, 2698-2701.

23. J. Jin, L.Chen and M.Song: J. Nanosci. Nanotechnol., 2009, 9, 6453-6459.

24. V.K.Anuganti and A.H.Velders: in Carbon nanotubes for biomedical applications, ed. R.Klingeler and R.B.Sims, Springer-Verlag, Berlin, 2011, pp. 128-130. 